\title{
Diskursus Relevansi Persaksian Perempuan Dalam Transaksi Keuangan
}

\author{
Mohammad Deny Irawan \\ Sekolah Pascasarjana UIN Syarif Hidayatullah Jakarta, \\ Konsentrasi Ushul Fiqh dan Hukum \\ E-mail:kimb22@yahoo.com
}

\begin{abstract}
ABSTRAK
Persoalan transaksi keuangan dalam Islam memiliki ketentuanketentuan tertentu untuk menunjung tingginya tingkat kepercayaan yang dilakukan oleh kedua belah pihak dalam bertransaksi. Selain tulis-menulis, persaksian juga berfungsi sebagai salah satu penunjang yang tidak bersifat wajib untuk menjaga kepercayaan dalam bertransaksi. Tulisan ini bertujuan untuk mendiskusikan sejauh mana persaksian itu dibutuhkan dan sejauh mana persaksian wanita itu dapat diaplikasikan. Dengan menggunakan metode penelitian literatur (literature review) dimana diskusi didasarkan pada tinjauan pustaka yang relevan dengan topik dalam tulisan ini. Penulis berkesimpulan bahwa persaksian wanita dalam transaksi keuangan diperbolehkan asalkan memenuhi ketentuan satu laki-laki dan dua wanita serta dua orang laki-laki yang direkomendasikan di awal berhalangan. Jika tidak, maka kesaksian wanita tidak dapat diterima.
\end{abstract}

Kata Kunci: Transaksi, fikih keuangan, persaksian wanita

\section{Pendahuluan}

Berbicara mengenai persoalan keuangan, tentunya, tidak terlepas begitu saja dengan pembagian yang terjadi pada transaksi keuangan serta tingkat kepercayaan orang yang bertransakasi (Zuhaili, 1985: 341). Dengan demikian, Islam menetapkan pondasi-pondasinya serta mempertimbangkannya secara syar'i dalam memandang proses transaksi keuangan tersebut (Al-Kibbiy, 2002: 140).

Dalam Al-Qur'an (Al-Baqarah[2]:282) dijelaskan bahwa Islam telah menetapkan gadai, tulisan, maupun persaksian sebagai alat bantu kepercayaan dalam transaksi keuangan yang dalam hal ini konteksnya adalah perkara hutangpiutang. Ayat ini dapat diartikan bahwa tulis-menulis dalam transaksi hutangpiutang merupakan suatu keharusan karena secara eksplisit hal ini menjadi sebuah acuan bahwa hutang-piutang menjadi sesuatu yang perlu di perhatikan 
sebagaimana persaksian juga di perlukan dalam transaksi keuangan (Ibnu Katsir, 2000: 508), (Imam Syafi'i, 2001: 179), (Al-Mawardi, 1994: 3).

Berdasarkan hal tersebut di atas, dapat disimpulkan bahwa persoalan transaksi keuangan dalam Islam memiliki ketentuan-ketentuan tertentu untuk menunjung tingginya tingkat kepercayaan yang dilakukan oleh kedua belah pihak dalam bertransaksi.

Selain tulis-menulis, persaksian juga berfungsi sebagai salah satu penunjang yang tidak bersifat wajib untuk menjaga kepercayaan dalam bertransaksi. Imam Syafi'i mengharapkan adanya persaksian dalam empat transaksi keuangan, yaitu; (1) gadai, (2) sewa, (3) mudharobah (bagi hasil), dan (4) wakalah (agensi atau perwakilan)(al-Mawardi, 1994: 4). Pendapat Imam Syafi'i tersebut merupakan antisipasi adanya perbedaan pendapat antara pihak-pihak yang bertransaksi, sehingga menimbulkan kerugian ${ }^{1}$ (Haidar, 2003: 337), (Bahansimiy, 1989: 19).

\section{Definisi Persaksian}

Persaksian merupakan salah satu alat untuk memperoleh kebenaran. dalam hal memutuskan sebuah permasalahan, saksi dibutuhkan disamping alat-alat bukti yang lain seperti petunjuk, surat otentik, keterangan ahli, ketrangan terdakwa dan lain sebagainya (Zuhaili, 1985: 516).

Persaksian dalam Islam dinamakan syahadah (شهادة) berasal dari kata "syahada-yashhadu” (شهُ - شيخد) yang berarti menetukan segala sesuatu sesuai dengan apa yang dilihat dan didengarkan (Ma'luf, 2007: 306). Sebagaimana di ungkapkan sayyid sabiq bahwa aplikasi persaksian perlu menggunakan pengelihatan dan pendengaran (Sabiq, 1999: 228). Selain itu, proses persaksian dalam Islam selalu berkaitan erat dengan keimanan seseorang. Maka dituntut jujur sesuai dengan apa yang dilihat dan didengar, jika hal tersebut tidak dilaksanakan maka persaksian tersebut tidak dapat di terima (Sabiq, 1999: 228)

Di sisi yang lain, Ali Haidar dalam bukunya Durorul Hukkam menyatakan bahwa secara bahasa persaksian atau syahadah (الشهادة) diartikan sebagai informasi atau kabar (الأخبار) yang bersifat kekinian (والحضر) (Haidar, 2003: 337). Maka persaksian secara bahasa dapat dipahami sebagai penentuan sesuatu sesuai informasi yang didapat dari indera pengelihatan dan indera pendegaran yang diaplikasikan dalam kata-kata.

Sedangkan secara terminologi, Ibnu Hajar Al-Atsqolaniy dan Syaikh Abdul Ghoni Al-Ghonimy berpendapat bahwa yang dimaksud dengan syahadah adalah informasi yang dapat dipercaya untuk menetapkan keputusan hukum dengan

\footnotetext{
${ }^{1}$ Persaksian adalah sebuah pengungkapan terhadap informasi atau kabar atau kejadian yang benar-benar terjadi.
} 
dengan bentuk kalimat "saya melihat" (أنشهد) (Bahansimiy, 1989: 18). Berdasarkan hal tersebut, dapat disimpulkan bahwa persaksian secara terminologi dipahami sebagai penginformasian terpercaya yang berfungsi sebagai alat penetapan atas kebenaran.

Berkenaan dengan rukun persaksian ulama berbeda pendapat, pendapat pertama di ungkapkan ulama hanafiyyah bahwa rukun persaksian satu yaitu penyebutan kalimat "saya melihat" dengan menggunakan form kalimat almudhoro'ah bukan menggunakan kalimat lampau "saya (tadi) melihat" karena penyebutan kalimat tersebut berfungsi untuk pernyataan infomasi yang bersifat 'شlهinian' bukan bersifat masa lampau seperti yang hadir dalam kalimat "شاهدت (Zuhalili, 1985: 556), (Na'mah, (-): 72), (Al-Gholayaini, 2008: 27).

Pendapat kedua dikemukakakan oleh Kautsar Kamil 'Ali (1988: 16) serta ulama syafi'iyyah menyebut kan bahwa rukun persaksian dibagi menjadi lima: (1) saksi itu sendiri, (2) yang dilihat (masyhudu 'alaihi), (3) yang berkepentingan dalam persaksian (masyhudu lahu), (4) alat-alat atau syarat-syarat persaksian (masyhudu bihi), (5) pengucapan kalimat (shighoh).

\subsection{Syarat persaksian}

Tidak semua orang mampu menjadi saksi sebelum memenuhi persyaratan sebagai berikut: (1) Baligh, (2) Berakal, (3) Ilmu (mengetahui apa yang ia persaksikan), (4) Mampu untuk berkata, (5) Mampu melihat, (6) Merdeka, (7) Muslim. $^{2}$

\subsection{Persaksian yang tidak diperbolehkan}

Ahmad Fatihiy Bahansimy, mengklasifikasikan tujuh golongan yang tidak diperbolehkan untuk menjadi saksi, antara lain: ${ }^{3}$ (1) Perksasian orang yang buta, (2) Persaksian terdakwa Qodzaf, (3) Persaksian orang fasik, (4) Persaksian orang yang tuli, (5) Persaksian orang yang bisu, (6) Persaksian orang yang lengah, (7) Persaksian orang yang mempunyai hubungan kerabat terhadap tersangka (Bahansimiy, 1989: 75-100)

Kemudian diantara sebab-sebab orang yang tidak diperbolehkan menjadi saksi mencakupi beberapa hal sebagai berikut: (1) Memiliki kedekatan hubungan keluarga, (2) Permusuhan, (3) Persaksian yang dilandaskan atas rasa marah, (4) Persaksian yang dilandaskan hubungan kesukuan.

\footnotetext{
${ }^{2}$ Kedewasaan pada laki-laki saat bermimpi dan kedewassan wanita saat kelurnya darah haidh, maka apabila sudah dewasa akalnya dianggap sebagai mukallaf, (Thonthowi, 2001: 128), (Zuhaili, 2006: 168)
} 


\section{Persaksian Wanita Dalam Transaksi Keuangan}

\subsection{Ruang lingkup persaksian wanita}

Persaksian wanita pada dasarnya tidak memiliki perbedaaan dengan laki-laki yang menjadi saksi, karena persaksian dipahami sebagai sarana untuk menentukan kebenaran atas sesuatu (Sabiq, 1999: 228). Namun terdapat perbedaan antara lakilaki dan wanita dalam aspek kedewasaan (bulugh), tingkat kelembutan, sifat lupa yang lebih dominan, serta kelengahan (Abu Yahya, 1990: 23). Dengan demikian ruang lingkup persaksian wanita hanya berlaku dalam beberapa hal: (1) Permasalahan kewanitaan yang didalamnya laki-laki tidak boleh menjadi saksi, (2) Permasalahan keuangan, yang didalamnya sangat mungkin terjadi interaksi antara laki-laki dan wanita karena luasnya ruang lingkup keuangan yang beredar dan berkembang di masyarakat, (3) Dalam perkara pidana. Pada dasarnya persaksian dalam perkara pidana dilakukan oleh laki-laki, tetapi ada sebagian ulama yang memperbolehkan adanya persaksian wanita dalam perkara pidana (Kamil Ali, 1988: 38).

\subsection{Transaksi keuangan yang membutuhkan persaksian}

Diskurusus mengenai transaksi keuangan, terkait dengan keberagaman bentuk yang dimilikinya. Hal ini tentunya yang menyebabkan perkembangan transaksi keuangan selalu dinamis. Implikasinya, tingkat kepercayaan terhadap keberagamana transaksi keuangan perlu dijaga (Al-Kibbiy, 2002: 5). Salah satu cara untuk menjaga keberagaman transaksi keuangan, agar tetap berada dalam 'track' yang benar adalah dengan adanya persaksian dalam transaksi (disamping tulisan, gadai jaminan) (Al-Mawardi, 1994: 4). Sebagaimana firman Allah Swt. dalam surah (Al-Baqarah[2]:282) yang menerangkan tentang permasalahan hutang-piutang perlu dijaga dengan penulisan, persaksian (Ibnu Katsir, 2000: $505)$.

Beradasarkan hal tersebut, penulis berkesimpulan bahwa esensi hutangpiutang perlu dijabarkan secara lebih rinci untuk menentukan beberapa transaksi yang membutuhkan adanya persaksian, maka digunakanlah metode sabru wataqsim $^{4}$ yang berusaha untuk mengambil esensi dari ayat hutang-piutang tersebut. Sebagaimana dikemukakan oleh Imam Al-Mawardi bahwa transaksi keuangan yang didalamnya diperbolehkan adanya saksi ada empat, yaitu (1) sewa (Ijaroh), (2) Gadai (Ar-Rahn), (3) Bagi hasil (mudhorobah), dan (4) Perwakilan (Wakalah) (Al-Mawardi, 1994: 4).

${ }^{4}$ Sabru wa taqsim yaitu mengumpulkan seluruh sifat yang berada antar 'aslu dan furu' yang memungkinkan untuk dijadikan 'illah kemudian dari berbagai sifat diatas di 'sortir' dengan mencocokkannya dengan asl dan furu' dan membuang yang tidak cocok dengan hal tersebut. Maka sifat terakhir yang cocok, dijadikan sebagai 'illatul hukmî.. (Zuhaili, 1985: 638) 


\subsection{Peran wanita dalam persaksian dalam transaksi keuangan}

Tidak dapat dipungkiri bahwa ruang lingkup persaksiaan wanita, sebagaimana yang disepakati ulama ada tiga, (1) masalah kewanitaan, (2) pernikahan, dan (3) masalah keuangan. (Imam Syafi' I, : 121). Pendapat mereka didasarkan pada firman Allah Swt. dalam surah (Al-Baqarah[2]:282). ${ }^{5}$ Ayat ini menyatakan bahwa persaksian wanita sangat mungkin dibutuhkan dalam bidang keuangan meskipun masih bersifat temporal. Setidaknya terdapat dua langkah yang digunaka untuk menganalisa persaksian wanita dalam transaksi keuangan, pertama: analisanya dengan menggunakan pendapat para mufasssirin (Ahli Tafsir), kedua: analisa dengan menggunakan pendapat para fuqoha' (Ahli Fiqih) sekaligus hukum yang beredar disekitar persaksiaan wanita itu sendiri.

Para mufassirin berpendapat bahwa firman Allah Swt. dalam surah (AlBaqarah[2]:282) tersebut berkaitan erat dengan hubungan antara manusia dalam lingkup hutang-piutang dan kewajiban untuk menulis segala bentuk transaksi keuangan, serta memperkuatnya dengan persaksian dengan memberdayakan dua orang laki-laki, jika berhalangan maka diganti dengan satu laki-laki dan dua wanita (Zuhaili, 1994: 49). Keikutsertaan wanita sebagai saksi dalam masalah keuangan ini pada dasarnya tidak terlepas dari luasnya aplikasi transaksi keuangan yang berkembang saat ini, hal ini sesuai dengan pendapat Ibnu 'Asyuro bahwa keikutsertaaan wanita dalam perkara keuangan tidak lain disebabkan karena banyaknya bentuk dalam transaksi (Asyuro, 1984: 109).

Selain itu, ayat tersebut juga merekomendasikan bahwa jika tidak ada dua orang laki-laki maka dapat digantikan dengan satu laki-laki dengan dua wanita, dan wanita tidak dapat menjadi saksi sendirian dalam perkara keuangan (Ibnu Hayyan, 1993: 326). Bahkan al-Halabiy mengatakan bahwa bahwa persaksian dua wanita tanpa diikuti dengan laki-laki dianggap kurang adil (Al-Halabiy, 1985: 655). Dari sini dapat dipahami bahwa perempuan dapat menjadi saksi dalam perkara keuangan.

Selanjutnya timbul pertanyaan mengapa dua wanita saja tidak dapat dijadikan saksi secara mutlak dan membutuhkan satu orang laki-laki sebagai bagian dari persaksian dalam perkara keuangan?. Hal ini disebabkan karena bahwa firman Allah Swt. dalam surah (Al-Baqarah[2]:282) berfungsi sebagai sarana untuk saling mengingatkan satu sama lain agar tidak terjadi kesalahan dalam persaksiannya.

Menurut Jalaluddin As-Suyuthi, wanita dalam melakukan persaksian tidak terlepas dari tabi'atnya secara umum yaitu lengah dan banyak lupa, dan Al-Quran berusaha untuk menjaga agar kedua sifat tersebut tidak terjadi dalam persaksian

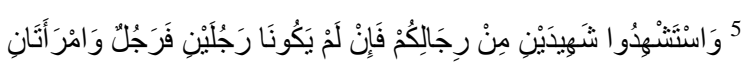


dan agar jika salah satu dari keduanya salah, maka saling mengingatkan. Hal ini didasarkan kepada hadits Rasullullah yang diriwayatkan oleh Abu Hurairah tentang kekurangan agama dan akal yang dimiliki wanita (As-Suyuthi, 2003: 339)

Sedangkan Hikmat bin Basyar berpendapat bahwa ayat 282 dari al-Baqarah dimaksudkan untuk menguatkan akad melalui tulisan, jika nantinya tulisan dianggap kurang untuk menguatkan akad maka persaksian dapat digunakan. Sedangkan dalam kaitannya mengenai dua wanita diperbolehkan menjadi saksi yang diikuti dengan satu orang laki-laki, hal tersbut disebabkan karena nilai persaksian wanita adalah setengah dari kesaksian laki, dengan demikian satu lakilaki dan dua orang perempuan cukup untuk menggantikan dua orang laki-laki yang menjadi saksi. Hal ini didasarkan pada hadits yang diriwayatkan oleh Abu Sa'id Al-Khudriy bahwa nilai kesaksian wanita adalah setengah dari kesakisan laki-laki (Hikmat, 1419: 391), (Al-Bukhari: 144). Pendapat ini dikuatkan oleh Ibnu Qayyim Al-Jauziyyah dalam Ad-Dhau Al-Munir 'Ala Tafsir yang menyatakan bahwa penentuan dua wanita dengan satu laki-laki dalam persaksian transaksi keuangan bertujuan untuk menyetarakannya dengan dua laki-laki yang dianjurkan dalam persaksian dan juga untuk saling mengingatkan satu sama lain jika terjadi kesalahan dalam kesaksian (Ibnu Qayyim: 491).

Oleh karena itu dari beberapa pendapat diatas dapat diambil kesimpulan bahwa persaksian wanita yang berjumlah dua orang yang diikuti dengan satu orang lakilaki bersifat temporal untuk menggantikan dua orang laki-laki jika berhalangan dan hikmah dibalik dua wanita yang menjadi saksi adalah karena Al-Quran mengingatkan agar meningkatkan kewaspadaan akan terjadinya kelengahan dan kelupaan dan juga menjaga hak-hak yang terjalin dari terjadinya sebuah akad antara manusia khususnya yang berkaitan dengan masalah keuangan.

Para fuqoha' juga sependapat dengan para mufassirin mengenai persaksian wanita dalam transaksi keuangan. Imam syafi'i dalam kitab al-Umm, Imam AlMawardi dalam Al-Hawi Al-Kabir dan Wahbah Zuhaili dalam Fiqh Islam Wa Adillatuhu berpendapat bahwa tidak diterima persaksian wanita karena karena tabi'atnya yang cenderung sering lengah dan lupa (Zuhaili, 1985): 570).

Ibnu Qoyyim berpendapat bahwa ketentuan satu laki-laki dan dua wanita dalam masalah keuangan berarti bahwa nilai persaksian dalam keuangan ini, lakilaki memiliki dua per tiga (2/3) bagian dalam 'hutang' tersebut dan dua perempuan mewakili satu per tiga (1/3) lainnya (Ibnu Qayyim, 2000: 278). Dengan demikian dapat dipahami bahwa para fuqoha'pun bependapat bahwa tidak diterima persaksian wanita dalam perkara keuangan meskipun berjumlah dua orang tanpa diikuti dengan satu laki-laki.

Berdasarkan analisa diatas, dapat disimpulkan bahwa persaksian wanita dalam transaksi keuangan diperbolehkan asalkan memenuhi ketentuan satu laki-laki dan 
dua wanita serta dua orang laki-laki yang direkomendasikan di awal berhalangan. Jika tidak, maka kesaksian wanita tidak dapat diterima.

\section{Kesimpulan}

Persaksian wanita secara definitif tidak berbeda dengan dengan definisi persaksian secara umum kecuali dalam hal kedewasaan yang berbeda (bulugh) dan kecendrungan lengah dan lupa yang dominan. Mengenani ruang lingkup persaksian wanita juga berbeda dan persaksian wanita hanya di khususkan pada ranah keuangan (maliyyah), kewanitaan (an-nisaiyyat), dan pernikahan. Dan menurut pendapat para mufassirin serta fuqoha memandang bahwa persaksian wanita dalam permasalahan keuangan diperbolehkan sepanjang disesuaikan dengan form satu laki-laki dan dua wanita dan dua orang laki-laki yang menjadi saksi berhalangan dan perlu untuk digantikan dengan satu laki-laki dan dua wanita. Wallahu a'lam bis-Showwab.

\section{Daftar Pustaka}

'Ali, Kautsar Kamil. Muhadhorot Fi Fiqh Muqorin, (Kairo: Thiba'ati jaami'ati azhar, 1988)

Abu Yahya, Muhammad Hasan. Hukmu Syahadatin Nisa Fiima Siwal 'Uqubaat Mimma Yathlu'u 'Alaihir Rijal Ghooliban Fis Syari'ah AlIslamiyyah, Majallatus Syari'ah Wad Dirosat Al-Islamiyyah, (Kuwait: Jaami'atul kuwait wad dirosat al-islamiyyah, 1990)

Ad-Dardir, Ahmad bin Muhammad bin Ahmad. As-syarhu shogir 'ala aqrobi masaliki Ila madzhabil Imam Malik, (Kairo: Darul Ma’arif, 1986)

ad-Dimasyqiy, 'Imaduddin abdul fida' Isma'il ibn Katsir. Tafsiru-l-qurani-l'adzim, (Kairo: al-Farooq al-Haditsah, 2000)

Al hanbaliy, Taqiyuddin Muhammad Ibn Ahmad Futuhy. Muntaha-L-Irodat Fi Jam 'i-L-Muqni' Ma'a Tanqih Wa Ziyadat (Riyadh: Muassasatu-rrisalah, 1418)

al-andalusy, Ahmad bin yusuf al-ma'ruf bis samin. Ad-Daru-L-Mushowwan Fi'ulumi-L-Kitabi-L-Maknun (Damaskus:Daru-1-Qolam, 1985)

al-andalusy, Muhammad bin yusuf as-syahir bi ibni hayyan. Tafsri Bahru-LMuhith, (beirut: Darul Kutub al-'ilmiyyah, 1993) 
al-Bashriy, Abi-l-hasan 'ali bin muhammad bin habib al-Mawardiy. Al-Hawi AlKabir Fi Fiqh Madzhabi-L-Imam As-Syafi'i Wa Huwa Syarhu Mukhtashor Al-Mazniy, (Beirut: Darul kutub al-'Ilmiyyah, 1994)

Al-Gholayaini, Syeikh Musthofa. Jaami'ud Durus al-'Arobiyyah, (Beirut: Darul Bayan, 2008)

Al-Ghonimiy, Abdul Ghoni. Al-Lubab Fi Syarhi-L-Kitab, (Beirut: al-Maktabah al-Ilmiyyah, tanpa tahun)

Al-Ghozali, Abi Hamid Ibn Muhammad Ibn Muhammad Bin. Al-wajiz Fi Fiqh Imam Syafi 'i, (Beirut: Darul Ghorb al-Islamiy, 1988) ,Al-washith Fil madzhabi, (Kairo: Darussalam, 1997)

Al-Jauziyyah, Ibnu Qayyim. Ad-Dhou Al-Munir 'Ala Tafsir, (Riyadh: maktabah Darussalam, tanpa tahun) Ibnu Qayyim. Jami’ul Fiqh, (Kairo: Darul wafa', 2000)

al-kibby, Sa'duddin muhammad. Al-Mu'amalah Maliyyah Mu'ashiroh Fi DhouiL-Islam, (Beirut: Al-Maktabah Islamiy, 2002)

Al-Qoilubiy wa 'Amiroh, Ahmad Syihabuddin Ahmad Bin Ahmad Bin Salamah Wa Syihabuddin Ahmad Al-Birlesiy Al Mulaqqob Bil. Hasyiyatani Fi Syarh Minhaji-T-Tholibin (mesir: syirkati maktabah musthofa al yaabiy al-halabiy wa auladuhu, 1956)

Al-Qurthubiy, Abi-L-Walid Ibnu Rusyd. Al-bayan Wa Tahsil Wa Syarh Wa Taujih Wa Ta'lil Fi Masaili-L-Mustakhrojah (Beirut: Darul Ghorb al-Islamiy, 1988)

As-Suyuthiy, Jalaluddin. Ad-Daarul Mushowwan Fi Tafsiri Bi Ma'tsur, (Kairo: Markazu Hijri lil buhuts wa dirosatil 'arobiyyah al-islamiyyah, 2003)

as-Syafi'iy, Muhammad Idris. Al-Umm, (Kairo: Darul wafa', 2001)

Bahansimiy, Ahmad Fatihiy. Nadzoriyyatul Itsbat Fil Fiqh-L-Jina'iy Al-Islamiy, (Kairo: Darus Syuruq, 1989)

Haidar, Ali. Durrorul Hukkam: Syarh Majallatu-L-Ahkam As-Syar'iyyah, (Beirut: Darul Jabal, 2003)

Ibnu 'Asyuro, Muhammad thohir. Tafsir Tahrir Wa Tanwir (tunis: dari tunisiyyah, 1984)

Ibnu Qudamah, Abi Muhammad 'abdullah bin ahmad bin muhammad. Al-Mughni (Kairo: Darul 'alami-1-kutub, 1997) 
46 | Moh. Deny Irawan

Ma'luf, Louis. Munjid Fil Lughoh Wal A'lam (Beirut: Daru-s-syuruq, 2007)

Na'mah, Fuad. Malkhos qowa'idul lughoh al 'arobiyyah, (Damaskus: Darul hikmah, tanpa tahun)

Sabiq, As-Sayyid. Fiqh Sunnah (Kairo: Darul Fath li A’lami-1-‘Arobiy, 1999)

Thonthowi, Mahmud Muhammad. Usul Fiqh Al-Islamiy, (kairo: maktabah wahbah, 2001)

Wizarotul Auqof Al-Islamiyyah. Mausu'ah Fiqhiyyah (kuwait: wizarotul auqof wa syu'un al-islamiyyah, 1983)

Zuhaili, Wahbah. Fiqh Islam Wa Adillatuhu, (Damaskus: Darul Fikri press, 1985) . Tafsirul Wajiz 'Ala Haamisyil Quranil 'Adzim, (Damaskus: Darul Fikr, 1994)

. Usul Fiqh Al-Islamiy (Damaskus: Darul Fikri, 2006) . Madkhol Fi Fiqh Jina'i Al-Islamiy, (Kairo: Mathobi'us syuruq, tanpa tahun) 